\title{
PRINCIPAIS CONCEITOS DA ABORDAGEM SISTÊMICA EM CUIDADOS DE ENFERMAGEM AO INDIVÍDUO E SUA FAMÍLIA
}

\author{
NURSING CARE TO THE INDIVIDUAL AND HIS/HER FAMILY: MAIN CONCEPTS \\ OF THE SYSTEMIC APPROACH
}

\section{PRINCIPALES CONCEPTOS DEL ABORDAJE SISTEMICO EN CUIDADOS DE ENFERMERÍA AL INDIVIDUO Y SU FAMILIA}

Sueli Aparecida Frari Galera* Margarita Antonia Villar Luis**

Galera SAF, Luis MAV. Principais conceitos da abordagem sistêmica em cuidados de enfermagem ao individuo e sua família. Rev Esc Enferm USP 2002; 36(2): 141-7.

\section{RESUMO}

Dada a ênfase atual na questão família surgiu o interesse de trazer para a discussão alguns conceitos que fundamentam a abordagem sistêmica em cuidados de enfermagem, que tem como principal instrumento a entrevista com a família. Os conceitos discutidos são: sistema, ser humano, família, saúde familiar, intervenção de enfermagem, hipóteses, circularidade, hipótese sistêmica e neutralidade. Procurou-se fornecer exemplos práticos que facilitassem a compreensão dos conceitos, bem como sua aplicabilidade.

PALAVRAS-CHAVE: Família. Cuidados de enfermagem. Enfermagem. Saúde da família.

\section{ABSTRACT}

With the current emphasis in the family question it is important to discuss some concepts underlying the systemic approach to the family nursing care, which has in the interview with the family its main instrument. In this paper the following concepts are discussed: system, human being, family, familiar health, nursing intervention, hypotheses, circularity, systemic hypothesis and neutrality. It was aimed to supply practical examples that could facilitated the understanding of the concepts, as well as its applicability.

KEYWORDS: Family. Nursing care. Nursing.. Family health.

\section{RESUMEN}

Considerando la enfasis actual en la cuestión familia surgió el interés en traer para la discusión algunos conceptos que fundamentan el abordaje sistémico en cuidados de enfermeria, que tiene como principal instrumento la entrevista con la familia. Los conceptos discutidos son: sistema, ser humano, familia, salud familiar, intervención de enfermeria, hipótesis, circularidad, hipótesis sistémica, neutralidad. Se buscd fornecer ejemplos prácticos que facilitasen la comprensión de los conceptos, bién como su aplicabilidad.

PALABRAS-CLAVE: Familia. Atencion de enfermeria. Enfermeria. Salud de la familia.

\footnotetext{
* Enfermeira Especialista junto ao DEPCHda EERP - USP. Doutora em enfermagem. E-mail: sugalera@eerp.usp.br

* Professora Titular do DEPCHda EERP - USP-
} 


\section{INTRODUÇÃO}

$\mathrm{Na}$ atualidade a enfermagem brasileira, nas mais variadas áreas, dentre elas a psiquiatria e saúde mental, tem se voltado para a família como um grupo de grande potencial de acolhimento e socialização de seus membros. A criação do Programa de Saúde da Família, a redução do tempo de internação, o incentivo para tratamentos ambulatoriais e para uma rede de suporte mais amplo e flexível na assistência a portadores de doenças crônicas são exemplos de mudanças que tem exigido a inclusão da família no plano de cuidados.

É visível nas publicações brasileiras o aumento do tema família em enfermagem psiquiátrica e saúde mental. Os trabalhos têm adotado a visita domiciliaria ou o grupo de familiares como principais meios para a intervenção e pesquisa. Como referencial teórico e metodológico, utilizam a abordagem humanista ${ }^{(1-2)}$, a abordagem fenomenológica(3), a materialista histórica (4), a sociométrica (5) e a tomada de depoimento pessoal (6). A escuta ativa é empregada em todos.

Dada a ênfase atual na questão família, a importância da inclusão deste grupo na assistência e a novidade do estudo dessa temática sob um olhar mais compreensivo e abrangente surgiu o interesse de trazer para a discussão alguns conceitos que fundamentam a abordagem sistêmica em cuidados de enfermagem, que tem como principal instrumento a entrevista com a familia.

Esta abordagem, desenvolvida por Lorraine M. Wrigth e Maureen Leahey na Unidade de enfermagem familiar da Universidade de Calgary, vem sendo utilizada como guia para a prática, ensino e pesquisa por diversas enfermeiras canadenses e de outros países. Este trabalho está fundamentado nos textos de Wrigth, Leahey (7), Duhamel (8) e, em bibliografias sugeridas pela segunda autora nas disciplinas que oferece no curso de pós graduação da Faculdade de Ciência em Enfermagem da Universidade de Montreal.

A abordagem sistêmica em cuidados de enfermagem se inspira na Teoria Geral de Sistemas, Teoria da Cibernética, em Conceitos de enfermagem e da Terapia familiar, principalmente nos trabalhos da equipe de Milão. Esta equipe, inicialmente composta por Mara Selvini Palazolli, Luigi Boscolo, Gian Franco Cechin e Giuliana Prata, insistia na necessidade de adotar uma conotação positiva para os comportamentos, na utilização de rituais, de prescrições de tarefas e de um intervalo mais longo entre os encontros com a família .

A teoria do conhecimento elaborada pelo biólogo Humberto Maturana e seus colaboradores também é outra referência importante da abordagem sistêmica em cuidados de enfermagem. Principalmente com suas idéias sobre o determinismo estrutural e de realidade entre parênteses.
A abordagem sistêmica reconhece que a relação entre a dinâmica familiar e uma problemática de saúde é complexa, sendo impossivel distinguir claramente os efeitos diretos de uma sobre a outra. Pode-se porém, observar uma co-evolução, na qual a dinâmica familiar influencia a evolução da doença e esta, por sua vez, influencia a dinâmica da família que sendo outra irá interferir na evolução da doença, num processo contínuo ao longo do tempo.

\section{PRINCIPAIS CONCEITOS}

\section{Sistema}

Um sistema pode ser definido como um complexo de elementos em interação mútua. Esta definição pode ser aplicada para o indivíduo, para a familia ou mesmo para a sociedade. Cada sistema pode se constituir de sub-sistemas e estar inserido em outros sistemas maiores 9 .

Nesta perspectiva, a família pode ser vista como um sistema que é parte de um outro maior e composto de muitos subsistemas. A familia é composta de muitos sub sistemas, como subsistema mãe e filho, o casal e os irmãos. Ao mesmo tempo, a família é uma unidade que faz parte de um supra-sistema que é composto pelos vizinhos, organizações, igreja, instituições de saúde, escola, etc. As fronteiras entre esses sistemas são definidas arbitrariamente e ajudam estabelecer quem está dentro e fora do sistema familiar e quais subsistemas e supra-sistemas são importantes para a família num determinado momento.

\section{O ser humano}

0 ser humano é compreendido como um sistema cujos componentes e suas relações formam a estrutura. Este sistema é dinâmico e sua estrutura está em contínua mudança de uma maneira determinada em cada instante nela mesma. Ao mesmo tempo, o curso que segue esta contínua mudança estrutural é modulado pelas interações do organismo de uma maneira que tem a ver com a natureza estrutural destas interações(10).

Os sistemas vivos são determinados por sua estrutura biopsicológica e tudo que se produz no interior desses sistemas depende dela. Isto é da estrutura. A mudança dentro de um sistema se produz segundo sua própria dinâmica interna ou suas interações com o ambiente, o qual também muda continuamente (8)

Segundo Maturana(11), toda entidade viva somente pode perceber, responder, pensar, acreditar e agir de acordo com os limites de sua estrutura única como um ser. Este conceito salienta que a realidade descrita por uma pessoa não existe independente dela, pois é uma reformulação de sua experiência. 
Conseqüentemente, a realidade que o indivíduo descreve não é uma "realidade objetiva", mas uma realidade entre parênteses, pois é uma reformulação de sua experiência vivida.

Com base nessa compreensão da realidade, uma crítica às pesquisas sobre família é que em muitas delas o pesquisador entrevista somente um familiar de cada família. Interpretam as respostas desse familiar como sendo a representação fiel da opinião da família. Se a realidade de cada pessoa é uma reformulação de sua experiência, é justo pensar que a opinião de um elemento da família e a interpretação que o pesquisador faz desta opinião não são, necessariamente, a representação de todo o grupo.

Além disso, estas pesquisas sugerem intervenções de enfermagem junto à família fundamentadas nas interpretações das entrevistas feitas com um membro do grupo. Novamente, percebe-se o problema da visão única, pois a intervenção sugerida para a abordagem da família está fundamentada somente no ponto de vista de um de seus membros.

\section{A familia:}

A família é definida como um grupo de indivíduos vinculados por uma ligação emotiva profunda e por um sentimento de pertença ao grupo, isto é que se identificam como fazendo parte daquele grupo. Esta definição é flexível o suficiente para incluir as diferentes configurações e composições de famílias que estão presentes na sociedade atual(12).

Uma analogia útil para compreender os conceitos da teoria de sistemas aplicados à família é a comparação com o móbile. Observando-se um móbile suspenso no ar vemos que ele é composto de várias peças se movem, umas mais rapidamente do que outras. Colocando-se a mão em uma das peças imediatamente influenciamos os movimentos de todas as outras e, após algum tempo, o móbile retoma seu movimento balanceado, mas não necessariamente na mesma direção de antes de ser tocado ${ }^{(7)}$

Assim como o móbile, a família é um todo composta de vários elementos ou membros. Uma mudança em um de seus membros afeta todo o grupo. Porém, a família tem habilidades para criar um balanceamento entre mudanças e estabilidade. Por exemplo, a ocorrência de doença mental é reconhecida como uma sobrecarga, um estresse para toda a familia. No início da doença ocorre uma desorganização familiar e, posteriormente, a família consegue reorganizar-se priorizando o cuidado de seu familiar portador de doença mental(13).

\section{A saúde familiar:}

A noção de saúde familiar depende do julgamento que o observador faz sobre a eficácia da adaptação dó grupo frente às mudanças ligadas aos ciclos da vida familiar, ao seu ambiente ou a uma problemática de saúde fisica ou mental. O observador pode ser um membro da família ou um profissional de saúde(12)

\section{A intervenção de enfermagem}

Diversos nomes têm sido utilizados para descrever o trabalho da enfermagem, tais como: ações, atividade, intervenção , tratamento, terapêutica. Duhamel(8); Wrigth, Leahey ${ }^{(7)}$ preferem o termo intervenção, definido-o como alguma ação ou resposta da enfermeira, incluindo ações terapêuticas, respostas cognitivas e afetivas que ocorrem no contexto do relacionamento enfermeira paciente e oferecido para o individuo, família ou comunidade onde a enfermeira trabalha.

É comum se afirmar que o objetivo da intervenção de enfermagem é efetuar mudanças que ajudem o cliente e a família darem respostas mais efetivas aos problemas de saúde. Segundo Duhamel(8), na perspectiva do conceito de determinismo estrutural, este papel da enfermeira precisa ser reconsiderado.

O profissional que acredita que a objetividade não existe além dos parênteses reconhece que não pode impor a sua própria realidade aos outros e que deve respeitar a de seus pacientes. Reconhecendo a unidade de realidade de cada um, a enfermeira pode contribuir com a sua percepção, para que eles descubram uma outra realidade. Esta contribuição poderá promover mudanças estruturais capazes de favorecer uma melhor adaptação à problemática em causa. Nesta perspectiva, o papel da enfermeira muda de agente que dirige a mudança para elemento participante deste processo, criando um contexto favorável para a mudança(8).

\section{A formulação de hipótese}

Hipóteses são enunciados específicos sobre como a dinâmica familiar influencia um problema de saúde e sobre como o problema de saúde influencia a dinâmica familiar num determinado momento. A enfermeira formula hipóteses para exprimir o resultado da análise que faz a partir das informações que obtém na interação com o paciente/família.

Segundo Duhamel(8), as hipóteses permitem fazer uma ligação entre os comportamentos, as crenças, os sentimentos e as experiências passadas do sistema familiar para explicar a dinâmica de uma família frente a uma situação qualquer. Um exemplo de hipótese para explicar a falta de aderência de um paciente às recomendações do profissional de saúde poderia ser uma ligação com a experiência passada do paciente com seu pai, que mesmo aderindo às recomendações acabou morrendo. Um raciocínio possivel deste paciente seria: meu pai atendeu às recomendações e mesmo assim morreu, então de que adianta seguí-las? 
A idéia de hipótese na abordagem sistêmica é oposta à idéia de hipótese da pesquisa experimental. Segundo Selvini-Palazoli(14), na terminologia da ciência experimental, uma hipótese é uma suposição não comprovada que é aceita para ensaio experimental. Ela serve de base para uma investigação posterior que poderá indicar se ela deve ser aceita ou refutada. Isto é, na pesquisa experimental uma hipótese é verdadeira ou falsa.

Dentro da ciência familiar, os fenômenos provocados pelas questões que o terapeuta faz durante a interação com base nas hipóteses que formulou e que testa através de suas perguntas definem essa atividade como experimental. Porém, os dados deste tipo de experimentação derivam ou provém das retroações imediatas (verbais e não verbais) que os "sujeitos" dão às questões colocadas pelo terapeuta, ou por suas reações retardadas resultantes das prescrições e rituais propostos no final da sessão (intervenções do terapeuta). Tanto as questões, como as prescrições e rituais tem por objetivo a verificação ulterior de uma hipótese que era tida como plausível até aquele momento.

Para Hoffman (15), esta definição coloca imediatamente um marco desconcertante em torno da terapia, na qual cada caso será semelhante com um experimento por si só. Uma "novela de mistério" na vida real. Porém, muito pouco pode- se afirmar sobre o final desta "novela" que está em constante movimento, modificando-se de tempos em tempos.

Portanto, na abordagem sistêmica a idéia de hipótese permanece específica à significação fundamental do termo com relação à sua raiz etimológica de suposição: uma hipótese é uma suposição feita como base para o raciocínio, sem referência a sua verdade como ponto de partida para uma investigação. Esta definição exclui explicitamente os critérios de veracidade ou falsidade da pesquisa experimental (14).

Uma solução, proposta pela equipe de Milão, para a questão dos critérios de veracidade da hipótese foi uma metáfora de Pirandello sobre a verdade: "existem tantas possibilidades de verdades quantos lugares desde os quais contemplá-la" (14).

Assim é que Duhamel8) salienta que a hipótese que a enfermeira formula ao utilizar a abordagem sistêmica se opõe ao conceito de hipótese da pesquisa experimental, pois sabemos que ela não é uma representação objetiva da dinâmica familiar. Ela representa somente uma das muitas explicações.

Esta explicação pode ter utilidade para a família no sentido de facilitar o processo de adaptação a uma situação, seja ela uma doença, a falta de aderência ao tratamento, os problemas relacionados ao abuso de álcool e droga, ou relacionados às fases de desenvolvimento do ser humano. A familia confirmará ou não a utilidade dessa hipótese. Uma hipótese pode ser muito útil quando enfatiza os recursos do sistema familiar. Por exemplo, o apoio emocional que os pais podem dar frente mudança de comportamento de um filho.

No momento em que a hipótese pareça explicar, justificar ou dar uma direção para o caminho atual dos fatos a família apresentará uma configuração distinta. Como o sistema familiar está em constante movimento, este momento significa que a hipótese original deve ser revisada ou, algumas vezes, suprimida, pois esta configuração distinta tende a mudar outras, desestabilizando o sistema familiar novamente ou, talvez, aprofundando seu autoconhecimento(15).

A hipótese é útil também para o terapeuta. Primeiro, é útil em seu poder de organização, pois oferece um esboço inicial sobre o qual o terapeuta trabalha as informações reunidas na interação com a familia, dando-lhe um fio condutor para realizar suas entrevistas. Em segundo lugar, sugere um possivel significado que o comportamento sintomático pode ter para esta família especificamente.

Deve-se ter cautela com esta segunda utilidade, pois dizer que o sintoma tem a função de representar alguma desorganização familiar é uma afirmação linear. Sabemos que os membros de uma família se envolvem com outros tantos fatores e nenhum deles pode se encontrar sob controle unilateral dos demais.

Selvini-Palazoli et al. (14) salientam que, do ponto de vista epistemológico, seria incorreto dizer que o comportamento de uma pessoa causa o de outra. Portanto, não se pode afirmar que um sintoma é causado por reações da família a ele, nem tampouco o contrário. Antes, é melhor dizer que todos estes comportamentos estão girando em uma pauta que é suportada mutuamente e que caracteriza o modelo de funcionamento familiar. Há de se ter a compreensão de que este é um processo no qual as atividades encaixam-se umas nas outras tão ritmicamente como o inalar e exalar o ar, a sístole e a diástole do coração.

Duhamel (8) ressalta que dentro da abordagem sistêmica não se busca a causa do problema, mas os fatores que freqüentemente estão presentes e o mantém. Freqüentemente os fatores que fazem durar o problema são diferentes daqueles que o causam. Assim, dentro da análise de uma problemática de saúde, o "como" é mais importante que o "porquê". As hipóteses tendem a dar conta do contexto dentro do qual a problemática de saúde evolui, isto é, das relações entre os diferentes sistemas e sub sistemas que contribuem, por exemplo, para a manutenção de um problema de saúde.

É aconselhável que as hipóteses sejam construídas junto com os membros da família. A participação do grupo familiar nesse processo favorece 
a elaboração de hipóteses compativeis com as crenças, valores e percepções do grupo em relação a uma dada situação. Hipóteses muito diferentes da percepção da família não carecem de credibilidade e são logo descartadas. Hipóteses mais próximas ou semelhantes às das famílias são susceptíveis de manter o status- quo.

\section{O principio de circularidade}

Segundo Wrigth, Leahey(7), os comportamentos dos membros da família são mais bem compreendidos a partir de uma visão de causalidade circular do que linear. Causalidade linear é definida como um evento (A) causando outro (B), sem que este tenha qualquer ação sobre A. Por exemplo, quando o relógio toca às 6 horas da tarde, a família rotineiramente se reúne para o jantar. O evento A (soar do relógio) causa o evento B (jantar em família), enquanto que $B$ não afeta $o$ evento A.

No modelo de causalidade circular, o evento B pode afetar o evento A. Por exemplo, se o marido se interessa pelos cuidados com a ostomia de sua esposa (evento A) e a esposa responde explicando-lhe os procedimentos diários (evento $B$ ), pode ser que o marido continue se interessando e oferecendo suporte a ela. Neste caso, temos o evento A causando B, que reforça A novamente.

Esta compreensão da circularidade é prevista dentro da teoria de sistemas, mas foi com a cibernética de primeira e de segunda ordem que o conceito foi aprofundado. A cibernética interessa-se pelos mecanismos reguladores dos sistemas e pelos processos de retroalimentação.

A diferença mais importante entre a cibernética de primeira e segunda ordem é aquela relativa à observação dos sistemas. Na cibernética de primeira ordem o observador considera-se separado do sistema observado, enquanto que na de segunda o observador entra na descrição do que é observado. Na cibernética de segunda ordem a unidade do tratamento contém ambos: o observador e o observado(16)

Se o observador entra naquilo que é observado, não há o que se poderia chamar de sistema observado isolado. Finalmente, uma vez que qualquer observador percebe o mundo através das lentes da cultura, da família e da linguagem, o produto resultante representa não algo privado e autônomo, mas uma "observação comunitária"(6).

Nesta perspectiva da cibernética de segunda ordem, a circularidade é definida como a capacidade do terapeuta de conduzir sua investigação com base nas retroações da família, em resposta às informações que ele solicita sobre as relações, as diferenças e as mudanças dentro das próprias relações ${ }^{(15)}$.

O princípio de circularidade refere-se ao fenômeno da retroação entre os membros da família e entre esses e a enfermeira. A enfermeira questiona os membros da família sobre suas relações e as respostas da família a estas questões guiarão a entrevista. Observa-se a circularidade na troca de informação entre a enfermeira e o sistema familiar e entre os diferentes membros da família que influenciam cada uma das pessoas ${ }^{(8)}$

Por exemplo, logo depois que se pergunta à mãe com filho portador de fibrose cística se os cuidados da criança tornaram-se muito exigentes para ela. O pai, que participa da interação, recebe a informação e reage a ela minimizando o fardo que os cuidados com o filho podem representar para ela. No seu entendimento, os cuidados estão bem compartilhados entre ambos e não considera plausivel que a esposa se queixe da sobrecarga que isto the causa. A mãe reage exprimindo sua raiva, afirmando que seu marido não contribui suficientemente nos cuidados da criança. Esta interação que ocorre na presença da enfermeira informa-lhe sobre a relação dos dois e guia suas questões e hipóteses sobre o funcionamento familiar. Desta maneira, a informação circula entre a enfermeira e os diferentes membros da família, cada um influenciando os outro(8).

Nesta perspectiva, o terapeuta não é um agente e o cliente não é um sujeito. Ambos formam um campo mais extenso em que terapeuta, família e um certo número de outros elementos atuam e reagem uns sobre os outros das mais diversas maneiras, pois cada ação e reação mudam constantemente a natureza do campo no qual residem os elementos deste novo sistema terapêutico ${ }^{(15)}$.

\section{Hipótese sistêmica}

Um dos princípios da teoria de sistemas afirma que o todo é maior do que a soma de suas partes. Assim, a família é um todo maior do que a soma de seus membros. Com base neste princípio, a abordagem sistêmica se interessa pelas relações entre os diferentes sistemas e sub sistemas presentes no sistema familiar para compreender melhor o funcionamento de cada um deles. As relações entre os membros do sistema familiar influenciam, de maneira significativa, os comportamentos, crenças e sentimentos de cada membro de uma família. Seguindo o princípio da circularidade, esses comportamentos, crenças e sentimentos influenciam, por sua vez, as relações entre os diferentes membro(8).

O profissional que ajuda uma familia a lidar com uma problemática de saúde formula hipóteses sobre as ligações entre os comportamentos, as crenças e os sentimentos do grupo familiar de um lado e, de outro a problemática apresentada. Este tipo de hipótese, é chamado de hipótese circular ou hipótese sistêmica(16)

Para formular as hipóteses sistêmicas ou circulares, é necessário estruturar a informação 
recolhida junto à família de maneira que ela possa espelhar a coerência da organização circular dos elementos do sistema. O exemplo a seguir ilustra uma hipótese sistêmica com enfoque sobre as crenças.

Uma esposa que acredita que seu marido deveria seguir as recomendações do profissional de saúde para manter sua doença cardiaca em niveis mais equilibrados fala freqüentemente ao marido sobre os comportamentos que ele deve adotar para atingir os objetivos sugeridos pelo profissional de saúde. Apesar disso, seu marido continua negligenciando os conselhos terapêuticos e sua saúde não para de se deteriorar e os sintomas persistem.

Dentro deste caso, poder-se-ia formular a seguinte hipótese circular: as crenças da esposa em relação à saúde de seu marido e à recomendação do profissional de saúde são mantidas pela persistência dos sintomas cardiacos do marido ("ele não segue a recomendação, por isso é muito doente"). Reciprocamente, é possivel que a crença da esposa seja de natureza a manter os sintomas do marido, caso as tentativas dela de ajuda-lo sejam percebidas por ele como implicâncias. Neste caso, a reação do marido é recusar-se a seguir as recomendações. Com esta hipótese sistêmica ninguém é censurado e cada um, a sua maneira, contribui na manutenção da problemática de saúde que é a deterioração da saúde do marido.

Seria possivel formular hipóteses lineares, porém essas hipóteses tendem a não dar conta do fenômeno da circularidade dentro do sistema, levando, consequentemente, a uma postura de censura por parte de quem a propõe. Um exemplo de hipótese linear seria: o comportamento da esposa piora os sintomas do marido. Esta hipótese tem um caráter de censura em relação ao comportamento da esposa, cuja intenção seria a de ajudar o marido

Outra hipótese linear poderia ser: o marido não seguindo a recomendação da esposa provoca a piora de seu estado de saúde, reforçando a idéia da mesma. Hipóteses lineares são, freqüentemente, aquelas que os familiares adotam para explicar sua situação. Elas guiam seus comportamentos e influenciam suas interações, resultando em frustrações que podem manter a tensão dentro das relações.

As enfermeiras que buscam a causa dos problemas estarão mais predispostas a censurar um membro do sistema e adotar uma hipótese linear para explicar a problemática em questão. Estes profissionais correm o risco de comprometer a relação de confiança estabelecida com os membros da família. Entretanto as que procuram, desde o início, ligações circulares entre os diferentes elementos do sistema, influenciam mais facilmente a realidade dos membros da família, favorecendo um contexto propício à mudança ${ }^{(8)}$.

É importante ressaltar que, ao formular uma hipótese, a enfermeira deve utilizar uma linguagem que vise descrever a atitude de um membro da família. Dizendo, por exemplo, que a pessoa demonstra comportamentos que sugerem um estado depressivo, indicando para a família que a pessoa não é sempre assim.

\section{A neutralidade}

O princípio da neutralidade refere-se à necessidade da enfermeira ser imparcial frente ao sistema familiar, isto é, na interação com a família a enfermeira deve ter uma atitude que reflita respeito e interesse pela "realidade" de todos os membros do grupo de modo que cada um possa afirmar que a enfermeira não defende um membro em detrimento de outro.

Segundo Duhamel(8), a enfermeira que acredita que a objetividade não existe além dos parênteses terá mais facilidade para manifestar sua neutralidade, pois ela não considera que existe uma "verdade" ou uma visão que seria mais correta que a outra. Por isso, não julga que uma pessoa em particular seja responsável por um problema. Ao contrário, considera que é todo o sistema que o mantém.

Cechin(17) defende que uma atitude de neutralidade é mantida pela curiosidade, pois esta convida a uma busca contínua de hipóteses neutras que impedem a enfermeira de adotar uma descrição única do sistema analisado.

As enfermeiras, freqüentemente, visam convencer os pacientes a adotarem certos comportamentos, acreditando que existe uma visão correta da situação. Nessa concepção, poderá ser dificil dar provas de neutralidade e de flexibilidade no início da relação com a família. É impossivel ser curioso se existe a crença em uma única verdade (8).

\section{CONCLUSÃO}

Esta síntese teórica a respeito da abordagem sistêmica da família não teve a intenção de esgotar o assunto referente à temática, cuja literatura existente é testemunha de sua amplitude e complexidade. O objetivo foi, apenas oferecer uma visão dos conceitos principais e de sua aplicabilidade na enfermagem.

A abordagem sistêmica pode ser adotada mesmo que a entrevista seja somente com um membro da família. Por exemplo, poder-se- ia perguntar a um paciente: caso sua mãe estivesse aqui conosco o que ela responderia se eu Ihe perguntasse o que ela pensa sobre sua maneira de cuidar de sua doença? Porém, a abordagem familiar é preferivel à individual. A coleta de percepções de cada membro da família com relação à problemática vivida favorece a elaboração de hipóteses sistêmicas com maior potencial de utilidade à família do que as fundamentadas sobre a percepção 
de um só membro( $\left.{ }^{8}\right)$. É importante recolher a percepção de cada membro quanto ao funcionamento da familia, pois são elas que influenciarão os comportamentos de cada um e o funcionamento de todo o sistema familiar. A saúde familiar depende dessas percepções e deste funcionamento.

\section{REFERENCIAS BIBLIOGRÁFICAS}

(1) Silva LR. A prática de enfermagem com família dos usuários de saúde mental - visão do acadêmico de enfermagem. In. Labate RC, organizadora. Caminhando para a assistência integral. Ribeirão Preto: Scala; 1999. p. 349 - 362.

(2) Rocha EK. Em busca do equilíbrio da saúde mental. Divulgação em saúde para debate 2000; 19: 30-32.

(3) Schneider JF. Ser família de esquizofrênico - hermenêutica de discursos fundamentada em Martin Heidegger. [Tese] Ribeirão Preto (SP): Escola de Enfermagem de Ribeirão Preto da Universidade de São Paulo; 1999.

(4) Gonçalves AM. A mulher que cuida do doente mental em família. [dissertação] Belo Horizonte (MG): Escola de Enfermagem da Universidade Federal de Minas Gerais, 1999.

(5) Sgambati ER. Reinternação e rejeição familiar: um estudo com pacientes psiquiátricos. [Dissertação] Ribeirão Preto (SP): Escola de Enfermagem de Ribeirão Preto da Universidade de São Paulo; 1983.

(6) Sadgursky D. Desinstitucionalização do doente mental: expectativas da família. [Tese] Ribeirão Preto (SP): Escola de Enfermagem de Ribeirão Preto da Universidade de São Paulo; 1997.

(7) Wright LM, Leahey M. Nurses and families: a guide to family assessment and intervention. Third ed. Philadelphia: F. A.Davis Company; 2000.

(8) Duhamel F. La santé et la famille: une approche systémique en soins infirmiers. Montréal: Gaëtan Morin Editeur; 1995-

(9) Bertalanffy L. Teoria geral dos sistemas: aplicação à psicologia. In: Bertalanffy $\mathrm{L}$ et al., Editor. Teoria dos sistemas. Rio de Janeiro: FGV, 1976.

(10) Romesin HM. Da biologia à psicologia. Trad. de Juan Acunã Llorens. Porto Alegre: Artes Médicas; 1998.

(11) Maturana HR, Varela F. A árvore do conhecimento - as bases biológicas do entendimento humano. Trad. de Jonas Pereira dos Santos. Campinas: Editorial Psy II; 1995.

(12) Wright LM, Watson WL, Bell JM. The familiy nursing unit: a unique integration of research, education and clinical practice. In: Bell JM, Watson WL, Wright LM, editores. The cutting edge of family nursing. Calgary' Family Nursing Unit Publications, 1990.

(13) Oliveira AMN. Compreendendo o significado de vivenciar a doença mental na família. R Bras Enferm 2000; 53: 3-4.
(14) Selvini-Palazzoli M, Boscolo L, Cecchin G, Prata G. Hypothétisation - circularité - neutralité: trois directives pour conduire la séance. In: Selvini Palazzoli M, editorMara Selvini-Palazzoli históire d'une recherche: l'evolution de la thérapie familiale dans l'oeuvre de Mara Selvini Palazzoli. Paris: Editions ESF, 1987.

(15) Hoffman L. Faundamentos de la terapia familiar: un marco com ceptual para el cambio des sistemas. México: Fondo de Cultura Económica; 1994.

(16) Boscolo L. A terapia familiar sistêmica de Milão: conversações sobre teoria e prática. Trad. Carlos Arturo Molina-Loza, Christina Sutter. Porto Alegre: Artes Médicas, 1993.

(16) Tomm K. Circular interviewing: a multifaceted clinical tool. In: Campbell D, Draper R., editores Applications of Systemic Family Therapy: the Milan Approach. Orlando: Grude and Stratton Ltda, 1985.

(17) Cechin G. Hypothesizing, circularity and neutrality revisited: an invitation to curiosity. Family Process 1987; 26: 405-413.
Artigo recebido em 17/08/01

Artigo aprovado em 13/09/02 